\title{
A study on the micro tooling for micro/nano milling
}

\author{
Xiang Cheng • Zhigang Wang $•$ Kazuo Nakamoto • \\ Kazuo Yamazaki
}

Received: 13 November 2009 / Accepted: 21 July 2010 / Published online: 1 August 2010

(C) The Author(s) 2010. This article is published with open access at Springerlink.com

\begin{abstract}
Many researches have studied the micro tools either by simulations or experiments showing that the micro tools play very important roles in micro/nano machining, and micro tool geometries have a direct impact on the final machining quality. Commercially available micro milling tools are usually simply made from downsizing of macro milling tools, which may not be able to be accurately fabricated. Custom micro milling tools have been created by some researchers, but no design criteria for micro milling tools have been introduced. The above factors constrain the development of effective micro milling tools and consequently constrain the researches on micro/nano milling. Based on former researcher's work, this paper tries to introduce the design criteria for the custom micro tooling. Firstly, the extent typical micro milling tools are studied, and their drawback/limitations are summarized. Secondly, experimental evaluations of the key drawback/ limitations are processed. Thirdly, the design criteria for custom micro milling tools are proposed, and corresponding design process is introduced. Then, a new micro hexagonal end mill has been designed based on these criteria. Finally, a polycrystalline diamond micro hexagonal end mill with a diameter of $0.5 \mathrm{~mm}$ was fabricated by wire electrical discharge machining, and the evaluation experiments for the hexagonal end mill have been processed on a nano
\end{abstract}

\footnotetext{
X. Cheng $(\triangle) \cdot Z$. Wang $\cdot K$. Yamazaki

Department of Mechanical and Aeronautical Engineering, University of California, Davis,

One Shields Avenue,

Davis, CA 95616, USA

e-mail: cxcheng@ucdavis.edu

K. Nakamoto

Department of System Design Engineering,

Keio University, 3-14-1,

Yokohama-shi, Japan
}

milling center. Experimental results show the newly designed hexagonal end mill can achieve submicron level surface roughness and has simultaneously high-accuracy side and bottom machining capabilities.

Keywords Micro/nano machining $\cdot$ Micro tooling $\cdot$ PCD . WEDM

\section{Introduction}

Among mechanical micro/nano milling processes, micro/ nano milling is the most flexible one to create 3D features for applications such as MEMS (micro-electro-mechanical systems) and the die/molds for very high-accuracy glass products. One of the biggest challenges for mechanical micro/nano milling is the design and fabrication of high precision micro milling tools. The reason is that inappropriate design and fabrication will result in the long tool fabrication time and high cost due to the complicated tool fabrication processes, and even worse, it reduces the geometrical accuracy of fabricated tools, subsequently with these tools, it is difficult to achieve acceptable micro machining accuracy and surface quality. Many studies have been performed to fabricate or optimize the geometry of the micro/nano milling tools [1-8]. Although some suggestions are given based on the specific tool geometries in the literatures, no guidance criterion has been introduced for the custom micro tool design. Moreover, the commercially available micro milling tools are too expensive, and most of them are simply made from downsizing of macro milling tools. The above factors constrain the development of effective micro end mills, and consequently, the researches on micro/nano milling are constrained, so it is necessary to introduce design criteria for the custom micro tooling. 
In this paper, based on the study of existing typical micro milling tools, we summarized the drawback/limitations of these micro tools and did some experimental evaluations. Then, the design criteria for micro tooling were introduced in order to give basic guidance for the design of custom micro milling tools. Based on the guidance introduced in this paper, we designed and developed the new hexagonal end mill with symmetrical geometry, which has two cutting edges at the bottom and six cutting edges at the peripheral. The new hexagonal end mill has uniform axial rake angle, axial clearance angle, radial rake angle, and radial clearance angle, making the same surface quality possible for both side and bottom surfaces to be machined.

A polycrystalline diamond (PCD) hexagonal end mill with a diameter of $0.5 \mathrm{~mm}$ has been fabricated by a multiaxis wire electrical discharge machining (WEDM) machine. Micro/nano milling experiments on tungsten carbide (WC) have successfully shown the new hexagonal end mill can achieve submicron level surface roughness for both side and bottom surfaces.

\section{Summarization of typical micro milling tools}

\subsection{Literature review}

Based on our literature searches, the following literatures associated with design and fabrications of micro milling tools are reviewed and summarized.

In [1], a kind of simple oblique-cut micro mill (Fig. 1a) was fabricated and evaluated by grooving and spiderpattern machining on the workpiece made of aluminum. In [2], a kind of single-edged micro milling tool was developed to avoid possible problems prompted by multiedged micro milling tools with insufficient micro tool fabrication accuracy (Fig. 1b). Milling tools with diameters of 300 and $45 \mu \mathrm{m}$ were used for the grooves machining in order to verify these designed tools. In [3], the two-flute helical end mill has been optimized based on the dynamic load and strain analysis by finite element method (FEM). The optimized helical end mills made of WC coated with TiAlN were tested to cut the PMX190CrVMo20 with the hardness of 52HRC and 62HRC. In [4], a kind of two-flute end mill was created by the integration of WEDG and FIB sputtering (Fig. 1d). The fabricated micro tools were used to mill micro channels on polymer and average surface roughness Ra of $80 \mathrm{~nm}$ can be achieved. In [5], super finish ball-nosed end mill (SFB) and super speed ball-nosed end mill (SSB) are created (Fig. 1e). The SFB has a very simple no-flute unchamfered cutting edge with a large negative rake angle of approximately $-45^{\circ}$. The SSB has the same cutting edge as the SFB but its rake angle is approximately $-20^{\circ}$. Both tools made of CBN are tested to cut the die steel

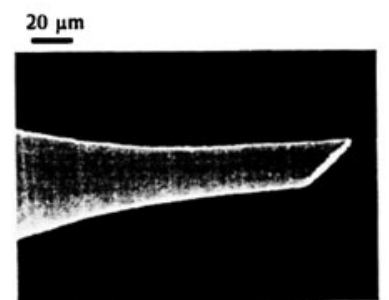

(a) SOC mill

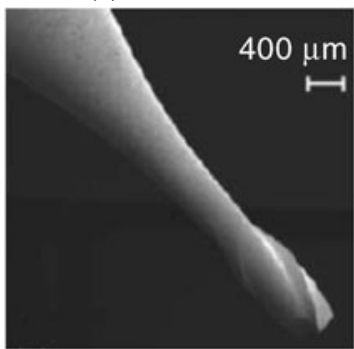

(c) Optimized helical end mill

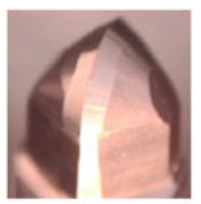

(e) SFB \& SSB

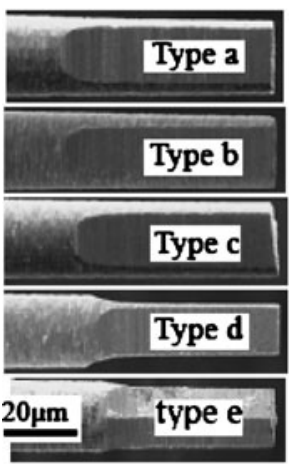

(g) $20 \mu \mathrm{m}$ end mills

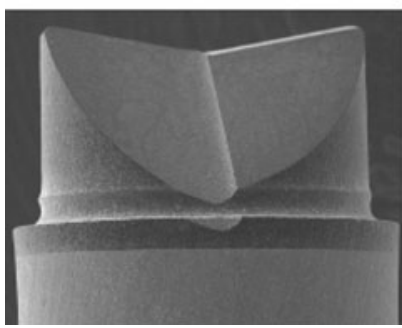

(i) Two-flute end mill

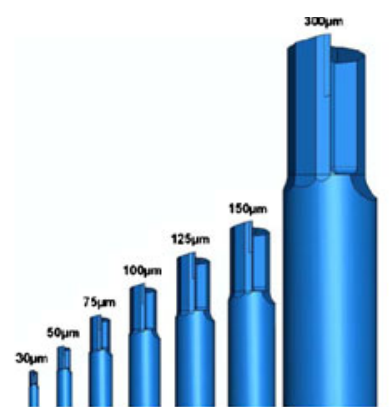

(b) Single-edged end mill

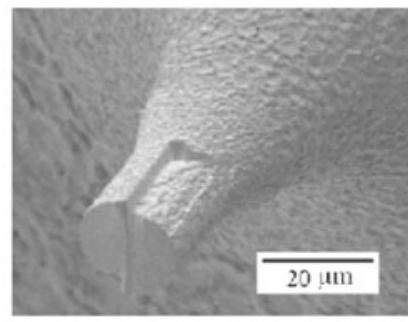

(d) Two-flute end mill
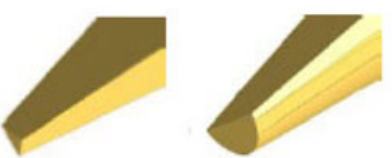

(f) $\Delta$-type and D-type end mill

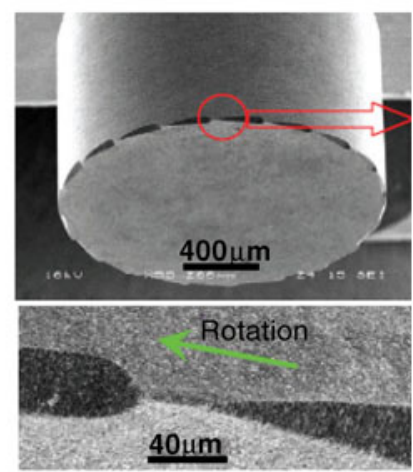

(h) 20-edged end mill

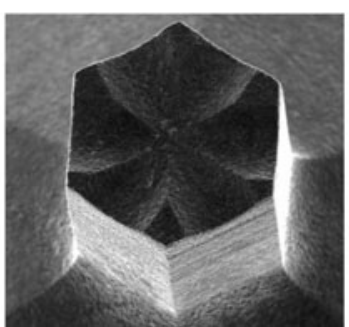

(j) Hexagonal end mill
Fig. 1 Micro milling tools from the literatures

SKD11 (60HRC) and hardened stainless steel STAVAX (52HRC). The best surface finish achieved by the SFB and SSB has approximately an $\mathrm{Rz}$ of 1.8 and $1.0 \mu \mathrm{m}$, respectively. In [6], $\Delta$-type and D-type end mills are 
Fig. 2 Commercially available micro two-flute helical end mill $(\Phi 0.1 \mathrm{~mm})$

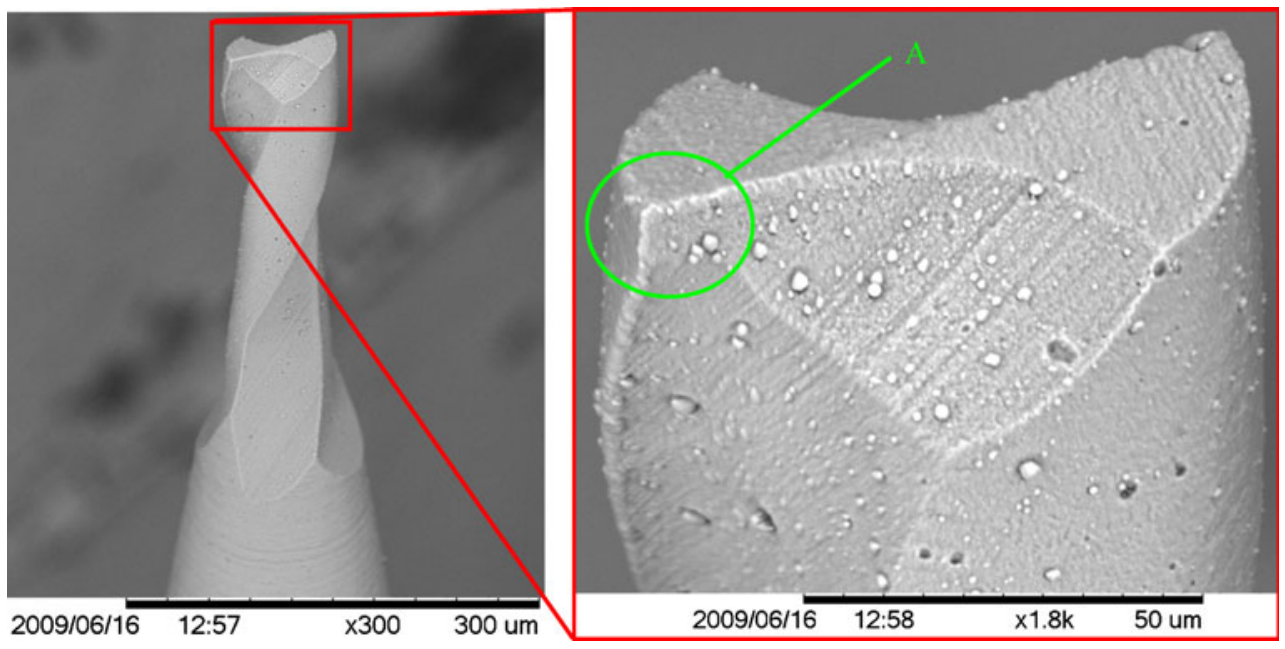

created based on the FEM analysis (Fig. 1f). The end mills made of WC are evaluated by cutting brass. The best surface roughness Ra of $100 \mathrm{~nm}$ can be achieved. Experiments show that the $\Delta$-type end mill is not appropriate for the machining of brass because of its large negative angle, which made the machined surface worse. The D-type end mill has both higher rigidity and better cutting performances. In [7], based on the $\Phi 20-\mu \mathrm{m}$ WC cylinder, four types of micro end mills were created by grinding method aiming at micro grooving on duralumin. By the experimental results, this paper gave three suggestions to the optimal tool shape for micro grooving, and the type e was created and tested to achieve a higher surface quality and longer tool life (Fig. 1g). In [8], a 20-edged micro milling tool made of PCD is ground and polished with diamond wheels (Fig. 1h). The experiments show that the micro aspherical mold and the micro lens array mold obtained were less than a P-V of $100 \mathrm{~nm}$ and an Rz of $15 \mathrm{~nm}$. In [9], two types of micro end mills are created by WEDM. One is the two-flute end mill used for very high-quality surface machining and another is the hexagonal end mill used for high-efficiency micro machining (Fig. 1i, j). Thin walls with a thickness of $3 \mu \mathrm{m}$ and height of $30 \mu \mathrm{m}$ were successfully machined, the side wall was machined by the $\Phi 0.2 \mathrm{~mm}$ hexagonal end mill and the bottom is finished by the $\Phi 1.0 \mathrm{~mm}$ two-flute end mill. The surface roughness with a P-V of $35.5 \mathrm{~nm}$ and an Ra of $2.8 \mathrm{~nm}$ for the bottom surface has been achieved.

From the above literatures, the micro milling tools are mainly randomly designed and fabricated without guiding criteria. Even though some good micro machining results have been achieved, the geometries and fabrication process for these micro end mills cannot be claimed as very effective. In order to efficiently guide the design of micro milling tools, the drawback/limitations of micro milling tool design are summarized.

\subsection{Drawback/limitations of available micro milling tools}

- Downsizing of conventional macro milling tools

Some available micro end mills are made directly from macro tools by downsizing. One of the typical ones is the two-flute helical end mill. Fig. 2 shows a brand new one of the commercially available two-flute
Fig. 3 Chips pasted to the rake faces (tool: PCD, workpiece: WC)

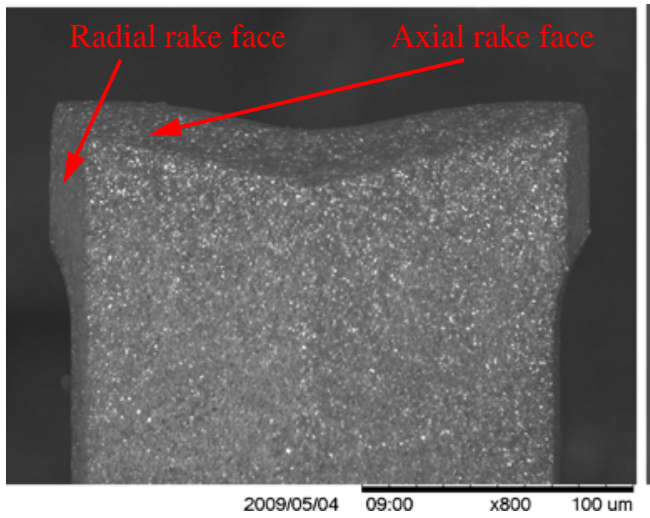

(a) Before machining

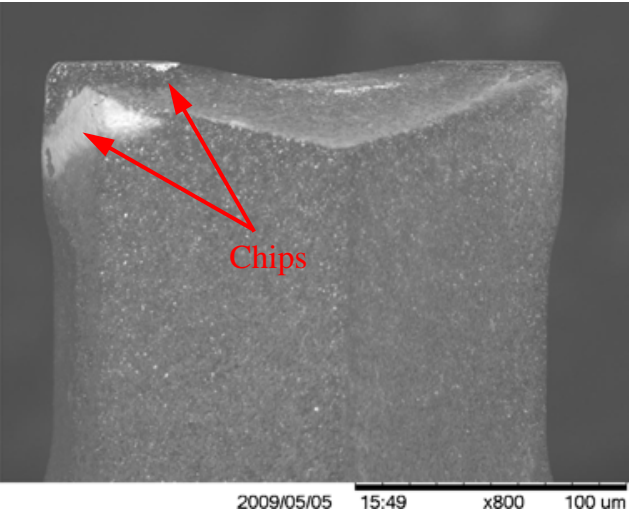

(b) After machining 
Fig. 4 Two-flute end mill (Ф0.9 mm)

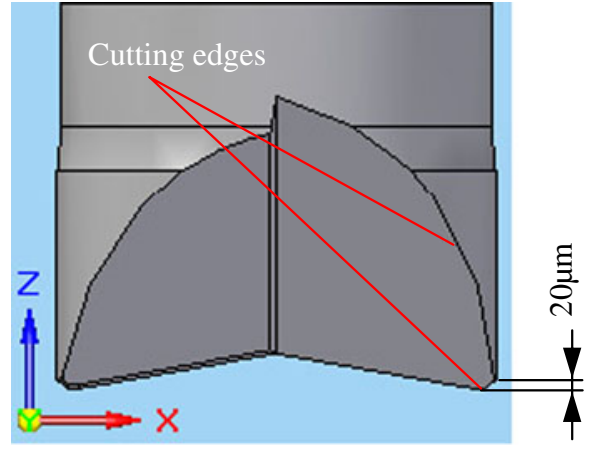

(a) Front view

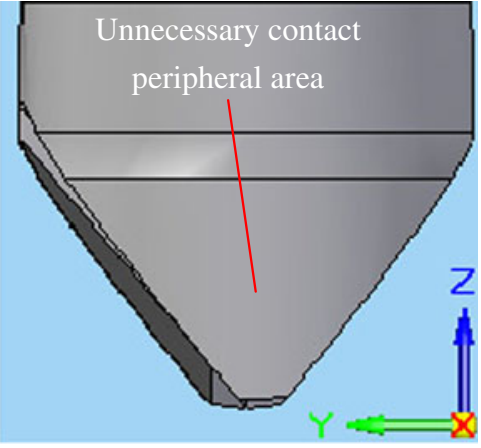

(b) Side view helical end mills with the radius of $50 \mu \mathrm{m}$. Area A in Fig. 2 shows that the side helical cutting edge has been overcut by the grinding wheel around $6 \mu \mathrm{m}$ of length in axial direction. At this area, the axial and radial rake angles are different from that of cutting edges outside area $\mathrm{A}$, which makes the cutting conditions changed and machining results varied along whole cutting edges in micro/nano milling processes. Moreover, the weak-point analysis showed that the simple downsizing of the conventional macro two-flute helical end mills is not appropriate for the type of load they have to withstand [3].

- Rake angle and cutting edge radius

Most of the micro tools mentioned above didn't consider the rake angles and cutting edge radius for the specific workpiece materials. As shown in the previous researches $[6,10,11]$, the rake angles and tool edge radius have significant relations to surface quality and cutting forces in micro/nano machining. They should be varied for ductile and brittle materials considering the different material removal modes.

- Critically small geometry features

Theoretically, the larger the micro milling tool is, the easier it is to fabricate the critically small geometry features, and the smaller the micro milling tool is, the harder it is or even impossible to create the critically small geometry features on the tool. For micro/nano milling, larger tools sometimes are inefficient or impossible to cut small features on the workpiece. Usually smaller-sized micro end mills with the diameter from $1 \mathrm{~mm}$ to several $10 \mu \mathrm{m}$ are preferred in micro/ nano milling. Micro tools shown in Fig. 1c, d, e, h, i, where SSB is presented in subpanel e, have size limitations because the rake face, one of the most important tool features affecting the tool performances, which on these tools is harder or impossible to be created by the original authors' machining methods due to the size limitations of the grinding wheel or electrode wire when the tool size becomes to several $10 \mu \mathrm{m}$.

- Unsymmetrical cutting edge geometries

As mentioned in [2], due to the manufacturing tolerances of $\pm 10 \mu \mathrm{m}$ on a micro tool, sometimes, only one cutting edge is engaged. This results in increased tool wear, increased cutting forces, minor surface quality, and a high risk of milling tool breakage, so the single-edged end mill is developed in [2]; however, the centrifugal load and deformation when the tool is rotating more than $100,000 \mathrm{rpm}$ cannot be neglected, especially for micro milling tools with comparatively larger sizes. This will result in the chattering of the tool
Fig. 5 Hexagonal end mill $(\Phi 0.5 \mathrm{~mm})$

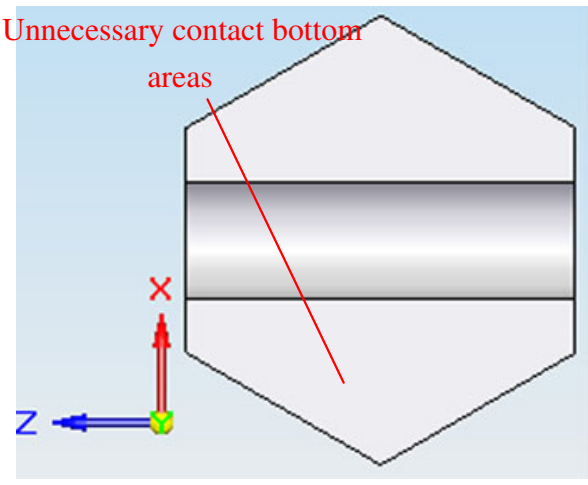

(a) Top view

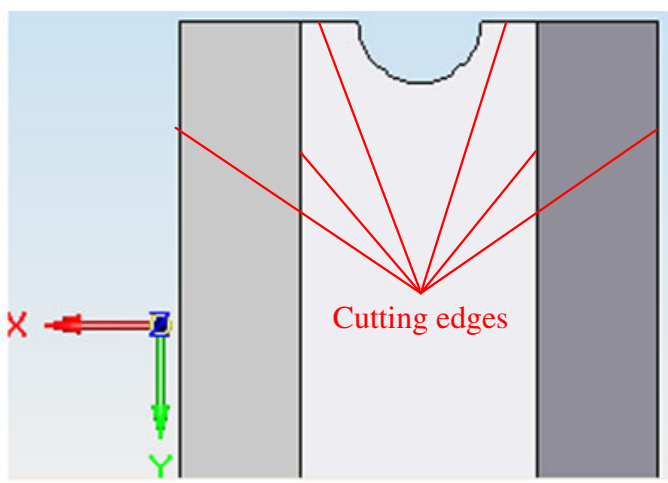

(b) Side view 


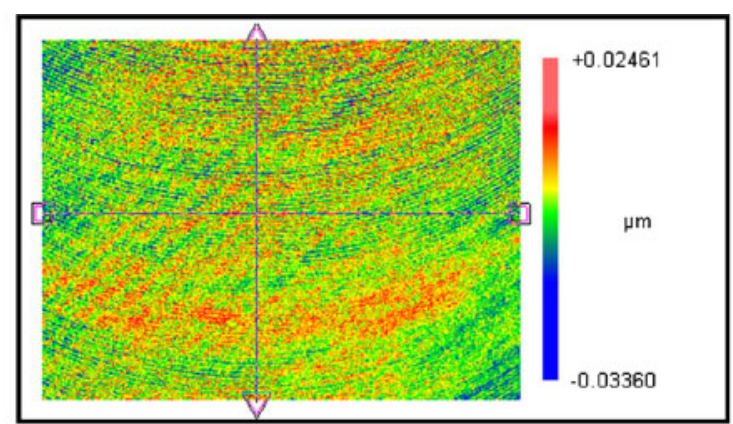

\begin{tabular}{|lcc|}
\hline PV & 0.058 & $\mu \mathrm{m}$ \\
\hline rms & 0.006 & $\mu \mathrm{m}$ \\
\hline Ra & 0.005 & $\mu \mathrm{m}$ \\
\hline Size X & 0.57 & $\mathrm{~mm}$ \\
\hline Size Y & 0.43 & $\mathrm{~mm}$ \\
\hline
\end{tabular}

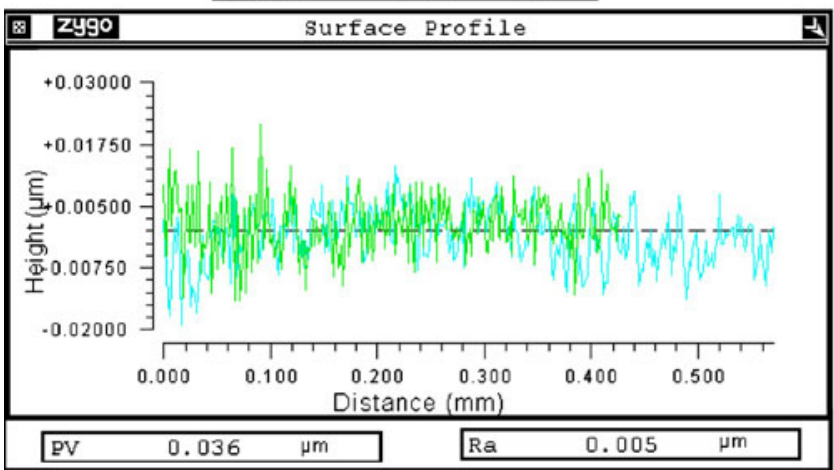

(a) Cutting depth $=20 \mu \mathrm{m}$
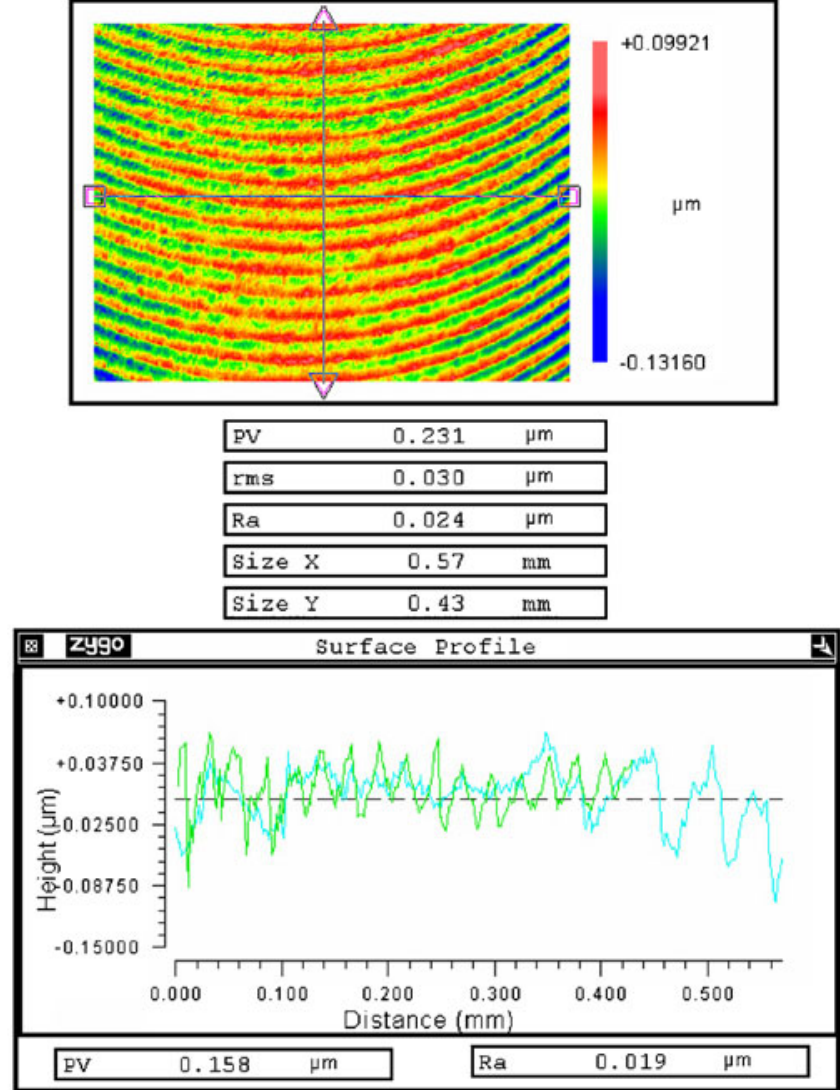

(b) Cutting depth $=35 \mu \mathrm{m}$

Fig. 6 Surface roughness by the two-flute end mill (feedrate $=0.2 \mu \mathrm{m} /$ tooth, $\mathrm{Ad}=1 \mu \mathrm{m})$

and, consequently, worsening the machined geometry accuracy and surface quality, so the unsymmetrical tool geometries mentioned in the literatures are preferred to ultra small-sized tools.

- Unnecessary contact between the tool peripheral and the workpiece
During cutting, the contact between the tool peripheral surface with the same radius of the radial cutting edges or the bottom surface with the same length of the axial cutting edges and the workpiece is called the unnecessary contact. Cutting forces increase obviously with the increase of the unnecessary contact between

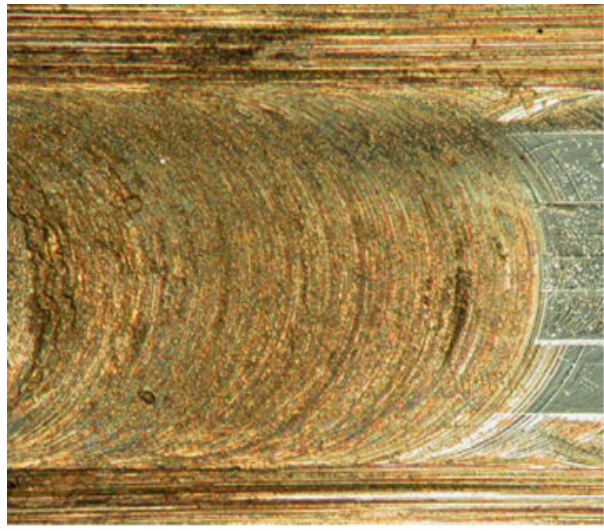

(a) Machined surface

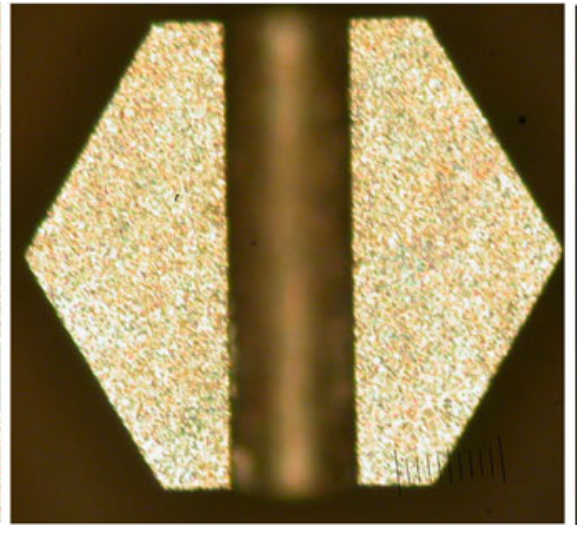

(b) Before cutting

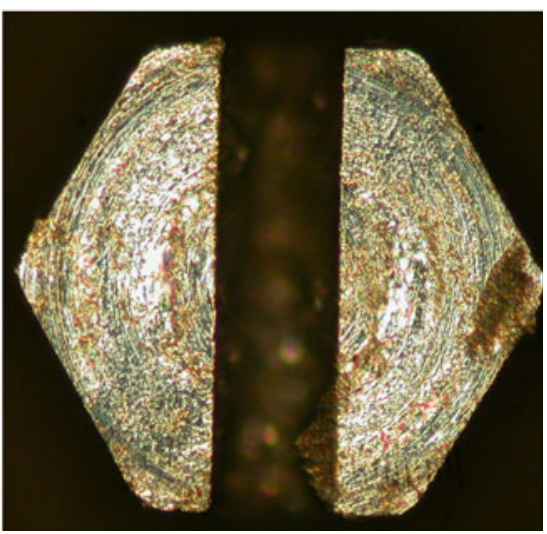

(c) After cutting

Fig. 7 Milling experiment by the hexagonal end mill (feedrate $=0.2 \mu \mathrm{m} /$ tooth, $\mathrm{Ad}=1 \mu \mathrm{m}$ ) 
Fig. 8 Design and development process for micro end mills

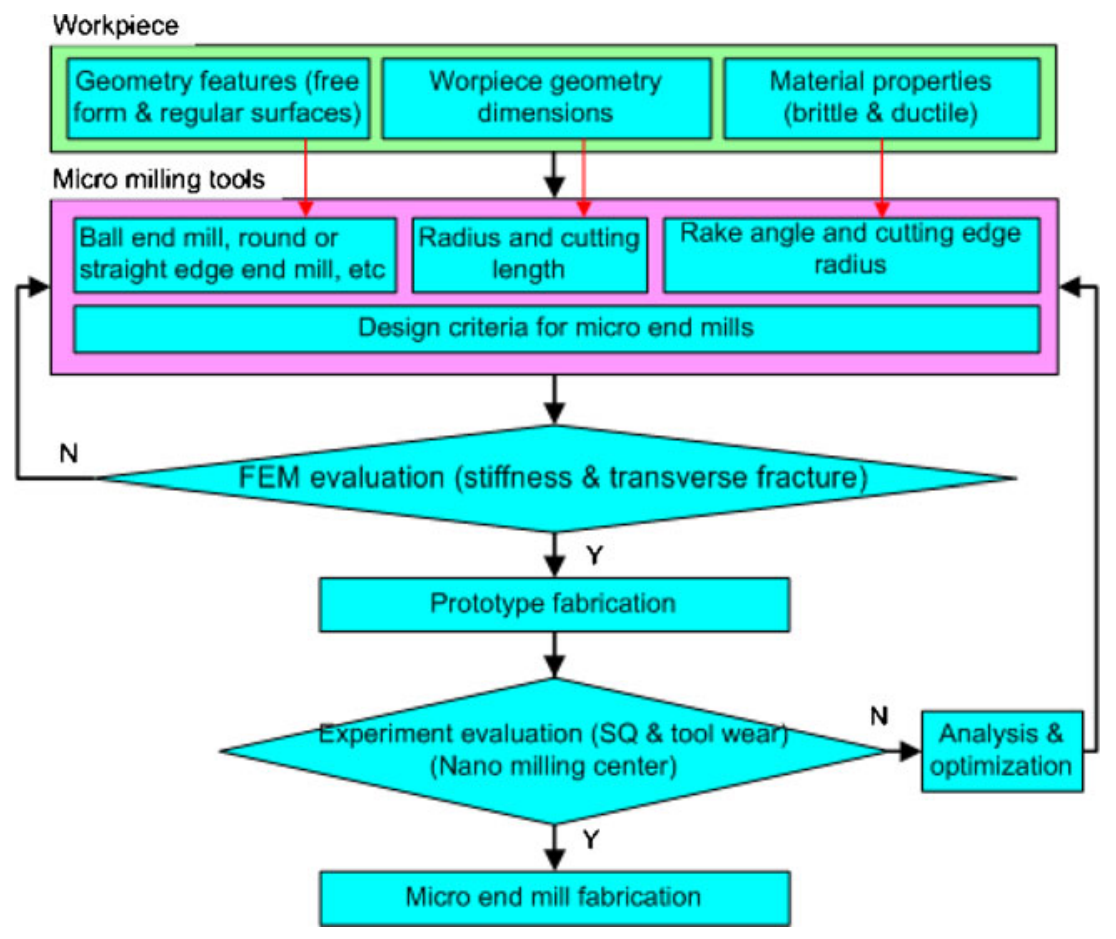

the tool peripheral and the workpiece, and also the burrs become more serious while the soft material is machined as mentioned in [7]. The tools shown in Fig. 1a, d, g, i, where types a, b, and c are presented in subpanel g, have such drawbacks. The larger the above tools are, the larger the unnecessary contact area and the worse the cutting situation are.

- Unnecessary contact between the tool bottom and the workpiece

In micro/nano milling, the feedrate per tooth is in micron or sub-micron level, so the length of cutting edges or the area of bottom faces of the tool are preferred to be as small as possible in order to avoid the friction and re-cut of the machined surfaces. The larger friction force between the bottom surface and the tool may cause the breakage of the tool, for example, when the micro PCD tools are used, where usually the cutting portion is made of PCD and the PCD is brazed to other materials such as $\mathrm{WC}$, the brazed portion is more possibly broken. Also, when the air turbine spindle is used for micro/nano milling, the larger friction force may cause the spindle stop. Considering the above two points of tool breakage and spindle stop, grooves have been cut for the hexagonal end mill in [9] in order to avoid as much as possible unnecessary contact between the tool bottom and the workpiece. The tools shown in
Fig. 9 New hexagonal end mill (Ф0.5 mm)

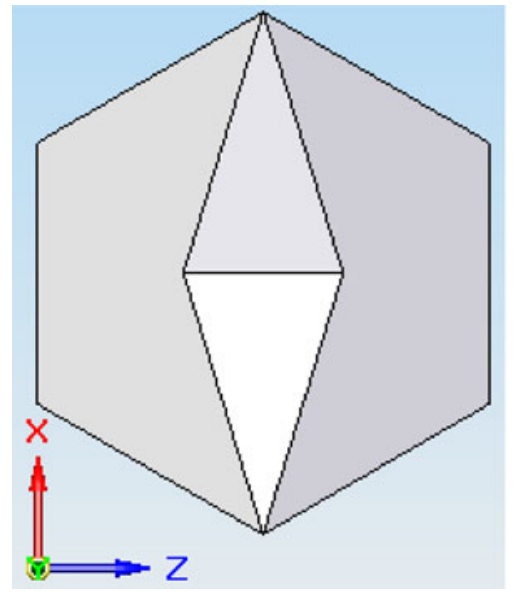

(a) Top view

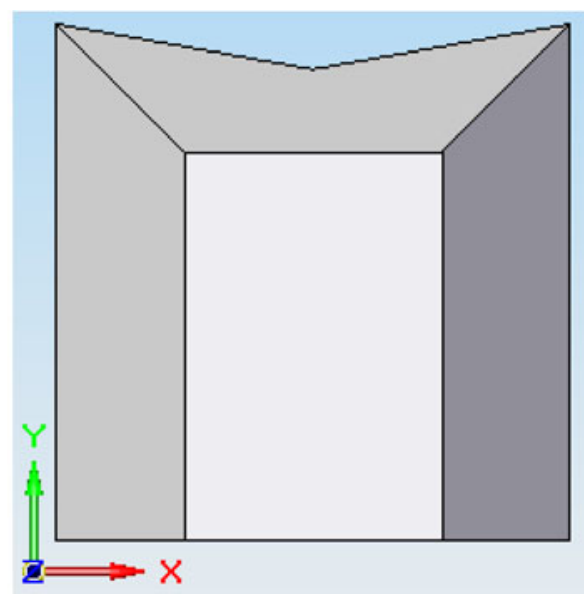

(b) Side view 
Table 1 Material properties

\begin{tabular}{lll}
\hline Material & WC & PCD \\
\hline Density $\rho\left(\mathrm{kg} / \mathrm{m}^{3}\right)$ & 11,900 & 500 \\
Elastic modulus E $(\mathrm{GPa})$ & 534 & 850 \\
Poisson's ratio $\nu$ & 0.22 & 0.08 \\
Transverse rapture strength Kc $(\mathrm{GPa})$ & 2.94 & 2.5 \\
Grain size $(\mu \mathrm{m})$ & 0.8 & 0.5 \\
\hline
\end{tabular}

Fig. 1f, g, j, where types a, b, c, and d are presented in subpanel g, have such drawbacks.

- Low chip disposal space

In micro/nano milling, the chips usually have the submicron-level dimensions, which make the disposal of chips very difficult even under flood fluid conditions. Figure 3 shows the chips are pasted to the axial and radial rake faces of the micro milling tool under flood fluid conditions, which were encountered by the authors. Even worse is that some micro/nano milling operations need to be finished without cutting fluid at all, so the dilemma is how to maintain the balance between a good chip disposal space on the tool and a good stiffness of the tool. Roughly, the tools

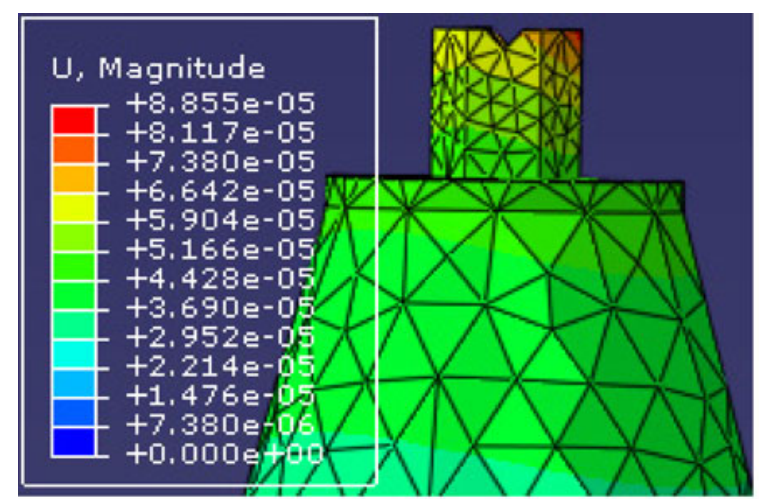

(a) Max. deformation (previous)

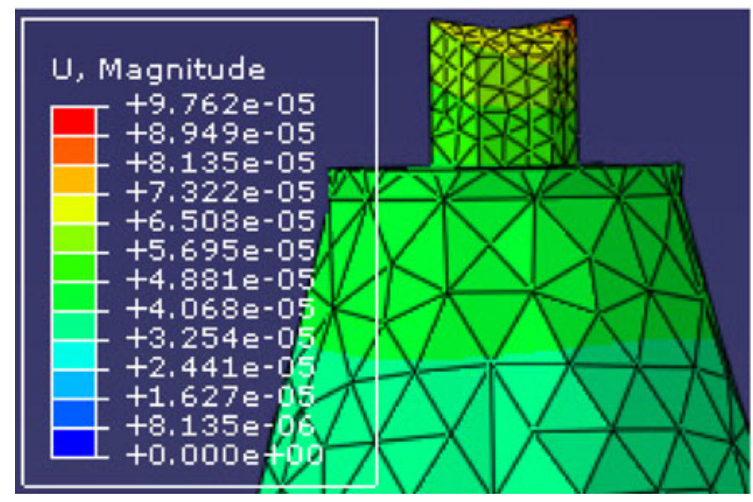

(c) Max. deformation (new) shown in Fig. 1b, d, h have the low chip disposal spaces.

- Machining efficiency

The ideal tool has multi-process capabilities, for example, only by one-time tool setup, the micro tool can machine the thin wall with both good surface finish on the side and bottom. The tools shown in Fig. 1i, j can only be used separately when micron-level thin wall features and sub-micron bottom surface finish are needed. The machining efficiency is lowered, and tool change errors will be introduced. For the same reason, tools shown in Fig. 1a, d, f have the similar drawbacks.

\section{Experimental evaluation}

Single-slot milling experiments are designed to evaluate the unnecessary contact effect. Figure 4 shows a successfully developed high-performance top surface milling tool, which has a larger unnecessary contact area while the cutting depth is larger than $20 \mu \mathrm{m}$. Figure 5 shows a successfully developed high-performance side surface milling tool, which has large unnecessary contact areas at the bottom.

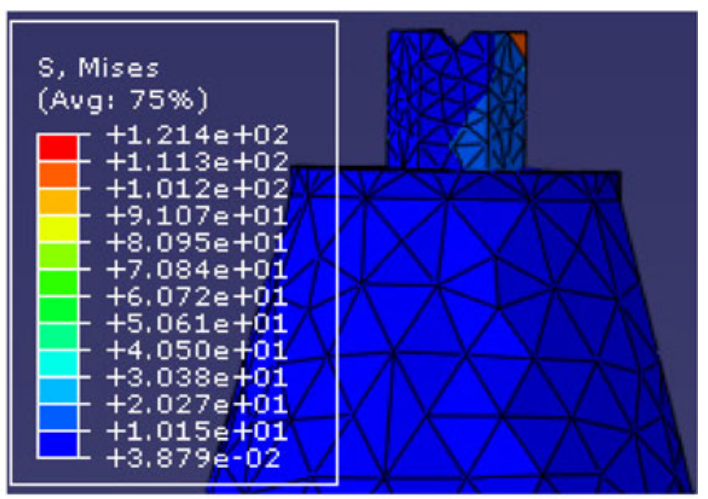

(b) Max. Mises stress (previous)

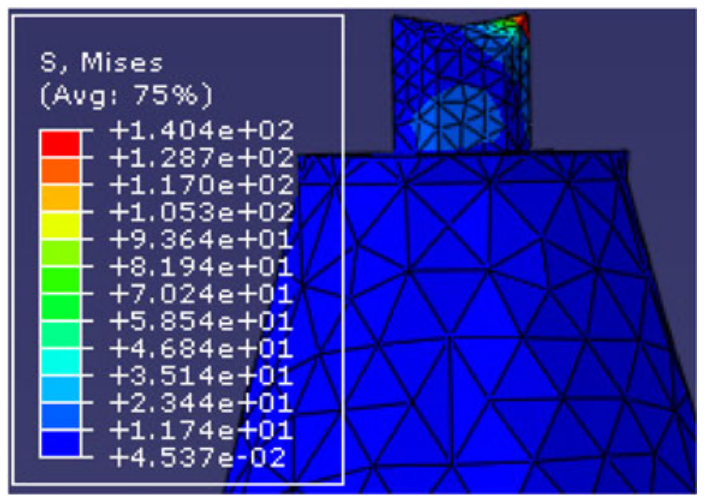

(d) Max. Mises stress (new)

Fig. 10 FEM static analysis 
Fig. 11 New hexagonal end mill made of PCD (Ф0.5 mm)

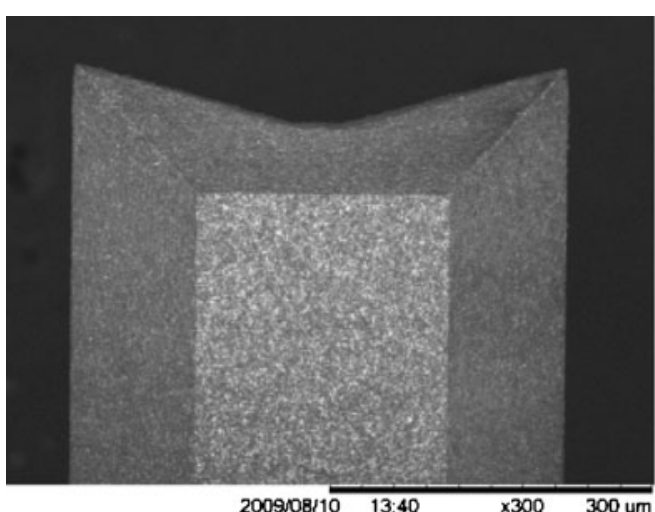

(a) Front view

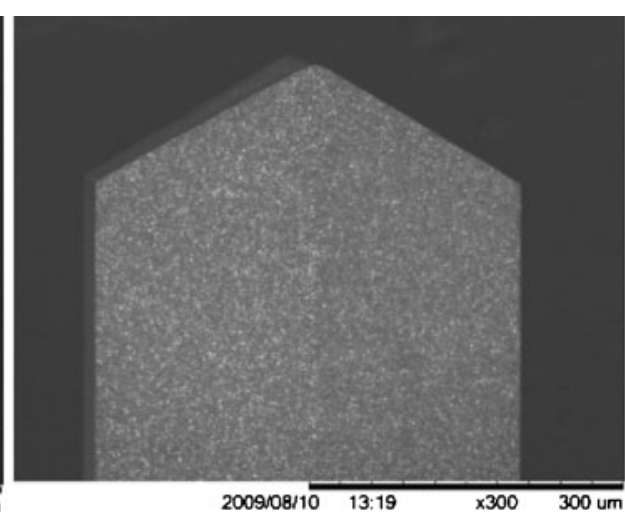

(b) Side view
Both end mills are made of PCD and fabricated by a dedicated multi-axis WEDM machine [9, 12]. The workpiece material is WC. The cutting experiments were done on the nano milling center AZ150 [9] and on machining conditions with feedrate $=0.2 \mu \mathrm{m} /$ tooth, Ad (axial depth of cut $)=1 \mu \mathrm{m}$, and spindle speed $=120,000 \mathrm{rpm}$; flood fluid and the micro tool are fully engaged during machining.

Figure $6 a, b$ shows the surface roughness by the twoflute end mill when the cutting depth is $20 \mu \mathrm{m}$ and $35 \mu \mathrm{m}$, respectively. When the cutting depth is larger than $20 \mu \mathrm{m}$, the unnecessary contact area becomes larger and surface roughness getting worse. When the cutting depth is larger than $40 \mu \mathrm{m}$, the noise can be heard, and spindle stops due to the friction forces. Figure 7 shows the bottom surface finish is very bad, and tool bottom wear is very serious due to the unnecessary contact at the bottom.

The experiments show the unnecessary contact is harmful to micro/nano milling and may cause bad surface finish, serious tool wear, and spindle stop.

\section{Design criterion and process for custom micro milling tools}

\subsection{Design criterion}

Based on the drawback/limitations mentioned above, the following design criteria are summarized in order to give a basic micro milling tool design guidance.

Table 2 Tool wear measurement

\begin{tabular}{lcr}
\hline & Radius (mm) & Length (mm) \\
\hline Before machining & 0.25072 & 29.15579 \\
After machining & 0.25064 & 29.15940 \\
Tool wear & 0.00008 & 0.00361 \\
\hline
\end{tabular}

- High stiffness

Stiffness plays a critical role in micro/nano milling. One reason for micro tool run-out is low stiffness. In micro/nano milling, tool run-out may cause only one cutting edge to be engaged during cutting. Consequently, the force variation increases significantly, the tool wears more quickly and probably results in tool breakage. Simply downsizing of conventional macro tools may cause this problem. During custom micro tool design for the specific micro machining purpose, it is necessary to make the stiffness of the custom tool equal to or higher than that of other similar-sized successful micro milling tools.

- Rake angle and cutting edge radius

Micro milling tools usually have a rake angle equals to or smaller than $0^{\circ}$ due to the stiffness reasons. Experiments showed that smaller negative rake angle made the machining quality poorer in micro/nano milling of soft materials [6]. But for a brittle material, in order to achieve the ductile mode machining and higher machining efficiency, highly negative rake angles are preferred $[10,11]$. The cutting edge radius is related to the tool material grain size and the tool fabrication processes. Sometimes it is hard to be accurately controlled and can only be passively measured and used for the calculation of machining parameters. In ultra-precision micro/nano milling, the axial depth of cut and the feedrate per tooth are sub-micron level, which makes the edge radius to form the effective rake angle, so for soft materials, smaller edge radius and larger rake angles from negative to $0^{\circ}$ are preferred. For hard and brittle materials, larger edge radius and highly negative rake angles are preferred.

- Critical small geometry features

Critical features need to be considered according to the machining capability, accuracy and efficiency, for example, the size of the smallest grinding wheels and 


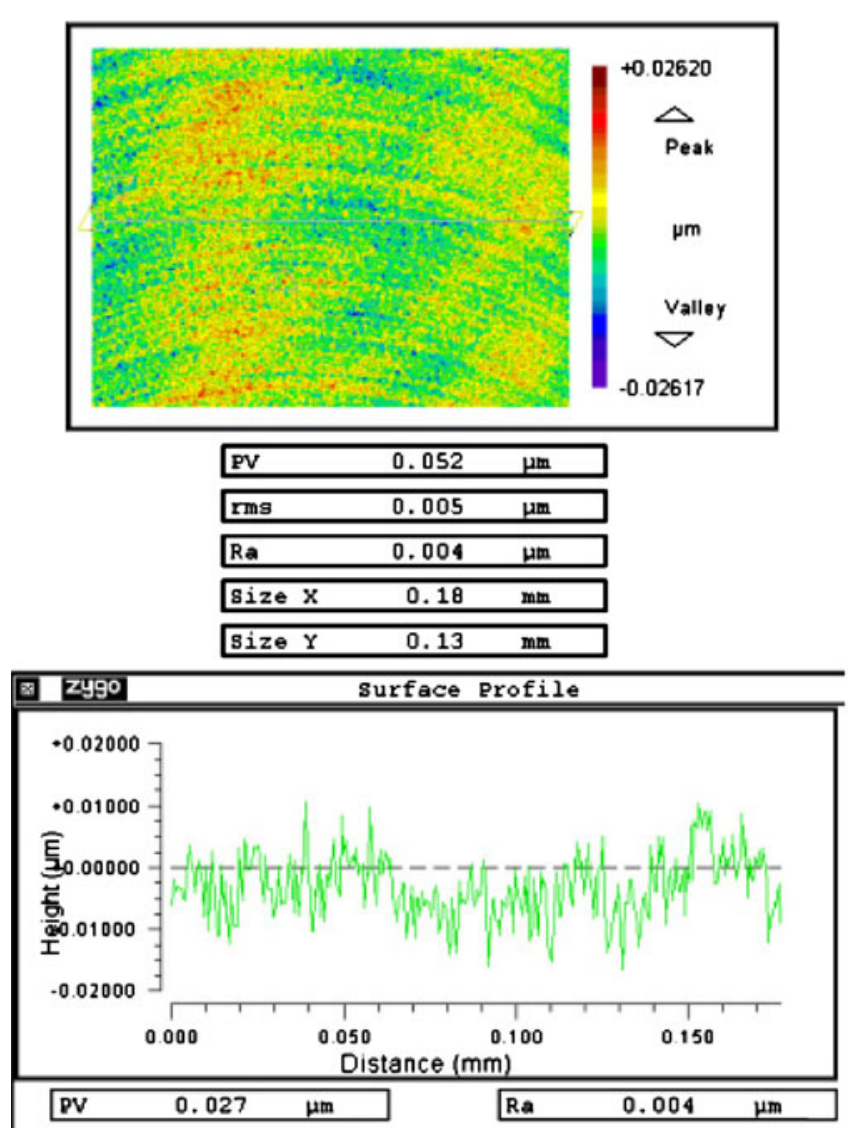

(a) Bottom surface

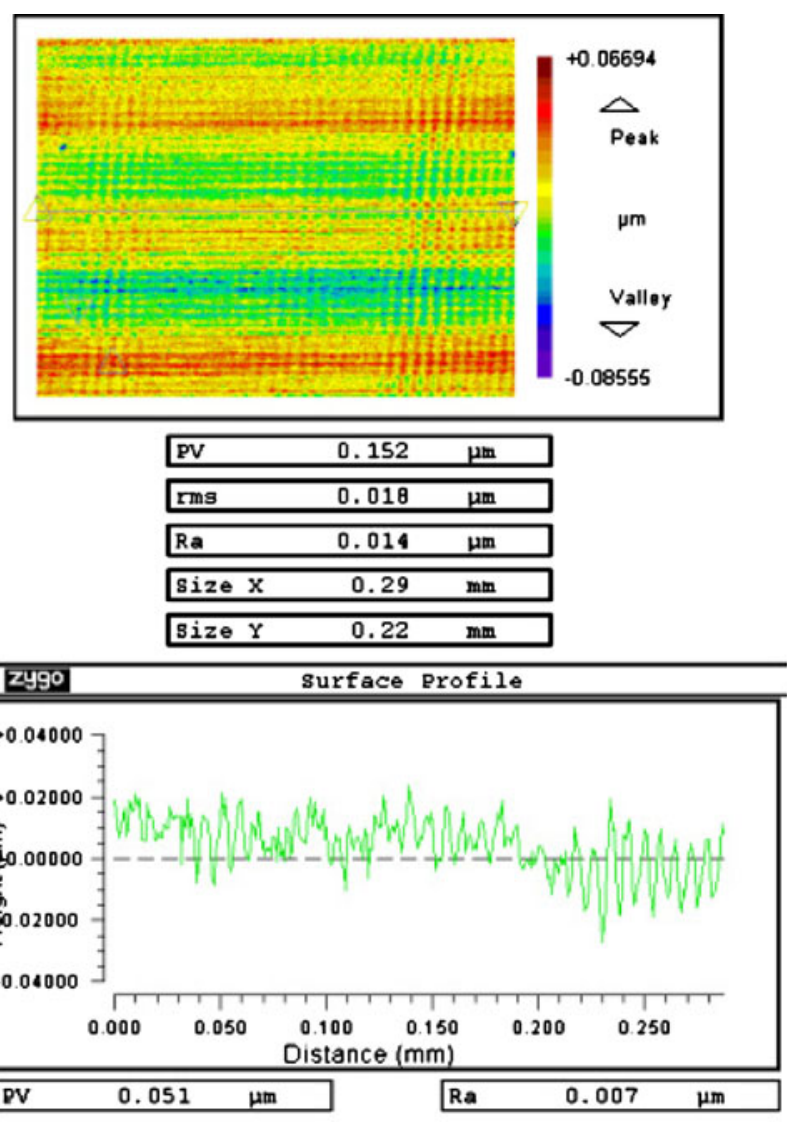

(b) Side surface

Fig. 12 Surface roughness of the slot (feedrate $=0.2 \mu \mathrm{m} /$ tooth, $\mathrm{Ad}=1 \mu \mathrm{m}$, total cutting depth=300 $\mu \mathrm{m}$ )

the thinnest electrode wire should be taken into consideration for smaller concaves in the micro tools.

- Symmetrical tool geometry

With the advantages of more precise machine tools and more optimal machining processes, cutting edge variation error of $\pm 3 \mu \mathrm{m}$ has been achieved for a SFB with a radius of $500 \mu \mathrm{m}$ in [5], radius error of $1.6 \mu \mathrm{m}$ has been achieved for a hexagonal end mill with a radius of $250 \mu \mathrm{m}$ in [12], and cutting edge variation error of $\pm 2 \mu \mathrm{m}$ has been achieved for a newly designed ball end mill in [13]. That makes it possible for fabricating micro milling tools accurately with symmetrical geometries. Considering good balances under very high rotation speed, symmetrical tool geometry is preferred.

- Avoid unnecessary contact

Clearance angles, tool peripherals, and tool bottom surfaces should be considered to avoid unnecessary contact.

- Chip disposal space

Chip disposal space before the rake face needs to be considered especially under severe cutting conditions as no cutting fluid and high-pressure air.
- Multi-process capability

Micro milling tools with single-tool multi-process machining capabilities are preferred to achieve high machining efficiency and accuracy by reducing the tool change time and errors.

\subsection{Design process}

Based on the above micro milling tool design criteria, the design process for custom micro milling tools is proposed as shown in Fig. 8. Given the workpiece information such as the geometry features, dimensions, and material properties, micro milling tools are designed. Then, the FEM analysis is processed to verify the stiffness and transverse fracture possibilities. If the stiffness is commensurate with similarly successful micro end mills and if no transverse rapture happens, the designed micro tool is fabricated and experimentally tested. Otherwise, it is modified until the requirements are satisfied. Mainly, the surface quality and tool wear are tested in the experiments. The process is repeated until the required custom micro end mill is created for specific micro/nano milling purposes. 


\section{Development of a new micro end mill}

\subsection{Geometrical design}

Geometrical feature on the workpiece is slot with submicron surface finish requirements for both side and bottom surfaces; the dimension of the slot that is length $\times$ width $\times$ height $=5.0 \times 0.5 \times 0.3 \mathrm{~mm}$, and the material is WC. Based on the design and development process shown in Fig. 8, the corresponding designed micro end mill is shown in Fig. 9, which is derived from the hexagonal end mill shown in Fig. 7 satisfying the design criteria proposed in this paper. The material for the micro end mill is PCD, diameter is $0.5 \mathrm{~mm}$, radial rake and clearance angles are $-60^{\circ}$, axial rake and clearance angles are $-60^{\circ}$, and cutting length is $0.5 \mathrm{~mm}$. The properties of WC and PCD are shown in Table 1.

\subsection{Evaluation}

First, comparison of FEM evaluations are done for the previous hexagonal end mill and the newly designed end mill. The mesh type is C3D4, and 0.3-N forces in $\mathrm{X}$ and $\mathrm{Z}$ directions (Fig. 9) are applied to the tip of the cutting edge. Simulation results are shown in Fig. 10. The newly designed micro end mill has almost the same stiffness as the previous one, and the difference between the two maximum deformations is only $9.07 \mathrm{~nm}$. The maximum Mises stress is within the transverse rapture strength, and no tool chip-off will happen.

After the FEM evaluation, the newly designed micro end mill was fabricated by the multi-axis WEDM machine tool ASX350L [12] and is shown in Fig. 11. Then, the micro/ nano milling experiment was done on the nano milling center AZ150. During cutting, the cutting edges are fully engaged. Machining conditions are that feedrate $=0.2 \mu \mathrm{m} /$ tooth and Ad $=1 \mu \mathrm{m}$, so the total machining length is $1.5 \mathrm{~m}$. Tool wear was measured by the Blum measurement system integrated on the nano milling center AZ150 and was shown in Table 2. The radius wear is smaller than that of the length wear. The possible reason is that the machining parameters are not optimum, and the sharp bottom cutting edges are more vulnerable to wear than side cutting edges. These possible factors will be studied and verified in the future companying with micro/nano milling simulations. The finished surface roughness is shown in Fig. 12, which shows that the bottom surface finish achieved by the newly designed hexagonal end mill is commensurate with that of the two-flute end mill as shown in Fig. 6. The side surface roughness is higher but the $\mathrm{P}-\mathrm{V}$ still follows in submicron level. One of the possible reasons for the rougher side surface is that the side surface is machined layer by layer with the height of $\mathrm{Ad}=1 \mu \mathrm{m}$, based on the machining processes mentioned above. Another possible reason is that the side cutting edge has a kind of line cutting effect instead of point cutting effect as that of the bottom cutting edges. Possible solutions include the modifications to the machining process and the tool geometry. For the tool geometry, the ideal side cutting edge should be similar to the bottom cutting edge, but it will decrease the tool stiffness and increase the possibility of chipping off of sharp tips at the intersection between the side and bottom cutting edges. This research is in process now.

From the experiment, the new micro end mill developed based on the design and development process is successful, which conforms to all the design criteria proposed in this paper.

\section{Conclusions}

Micro milling tool is one of the most important aspects affecting the successful application of micro/nano milling; however, no systematically study has been made about the design for micro milling tools. Based on the analysis of the extant micro milling tools, the drawbacks or limitations are summarized. Then, by the authors' and other researcher's experimental and simulation experiences, the design criteria and corresponding design process of micro milling tools are proposed as guidance. Based on the design and development process, the hexagonal end mill is modified, and a new micro end mill is created and fabricated. The micro/nano milling experimental results show the sub-micron level surface roughness can be achieved for simultaneously both side and bottom surfaces, and show the successful creation of the new micro end mill by the design and development process.

Open Access This article is distributed under the terms of the Creative Commons Attribution Noncommercial License which permits any noncommercial use, distribution, and reproduction in any medium, provided the original author(s) and source are credited.

\section{References}

1. Aoki I, Takahashi T (1999) Micropattern fabrication by specially designed micro tool, Proceedings of SPIE. Int Soc Opt Eng 3874:365-372

2. Fleischer J, Deuchert M, Ruhs C, Kuhlewein C, Halvadjiysky G, Schmidt C (2008) Design and manufacturing of micro milling tools. Microsyst Technol 14:1771-1775

3. Uhlmann E, Schauer K (2005) Dynamic load and strain analysis for the optimization of micro end mills, CIRP Annals. Manuf Technol 54(1):75-78

4. Ali MY, Ong AS (2006) Fabricating micromilling tool using wire electodischarge grinding and focused ion beam sputtering. Int $\mathrm{J}$ Adv Manuf Technol 31:501-508

5. Jin M, Goto I, Watanabe T, Kurosawa J, Murakawa M (2007) Development of CBN ball-nosed end mill with newly designed cutting edge. J Mater Process Technol 192-193:48-54 
6. Fang FZ, Wu H, Liu XD, Liu YC, Ng ST (2003) Tool geometry study in micromachining. J Micromech Microeng 13:726-731

7. Ohnishi O, Onikura H, Min SK, Aziz M, Tsuruoka S (2007) Characteristics of grooving by micro end mills with various tool shapes and approach to their optimal shape. Mem Fac Eng Kyushu Univ 67:143-151

8. Suzuki H, Moriwaki T, Yamamoto Y, Goto Y (2007) Precision cutting of aspherical ceramic molds with micro PCD milling tool. Annals of the CIRP 56:131-134

9. Cheng X, Nakamoto K, Sugai M, Matsumoto S, Wang ZG, Yamazaki K (2008) Development of ultra-precision machining system with unique wire EDM tool fabrication system for micro/nano millingmachining. CIRP Annals-Manuf Technol 57(1):415-420
10. Blake PN, Scattergood RO (1990) Ductile regime machining of germanium and silicon. J Am Ceram Soc 73(4):949-957

11. Liu X, Devor RE, Kapoor SG, Ehmann KF (2004) The mechanics of machining at the microscale: assessment of the current state of the science. Trans ASME V126:666-678

12. Cheng X, Wang ZG, Kobayashi S, Nakamoto K, Yamazaki K (2009) Development of a six-axis wire electrical discharge machining machine for the fabrication of micro end mills. Proc IMechE Part B: J Eng Manufacture 223:121-131

13. Cheng X, Wang ZG, Nakamoto K, Yamazaki K (2009) Design and development of micro pcd ball end mill for micro/nano freeform machining of hard and brittle materials. J Micromech Microeng 19(115022):10. doi:10.1088/0960-1317/19/11/115022 